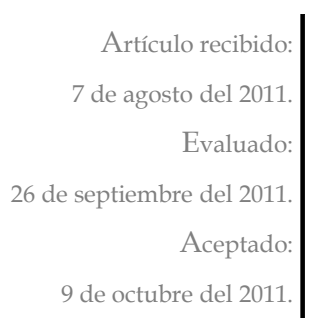

9 de octubre del 2011.

\section{El papel de las Comisiones Plenas en la dinámica legislativa en Costa Rica (1998-2010)}

RESUMEN

El presente texto pretende aportar en la comprensión de la dinámica de la Asamblea Legislativa de Costa Rica, por medio del estudio del rol de las Comisiones Plenas en la aprobación de leyes entre 1998 y 2010 Analizando la distribución y los cambios de las relaciones de poder provocadas por el transfuguismo parlamentario, se busca determinar los diferentes escenarios presentes en las Comisiones Plenas durante el periodo de estudio y su impacto en el proceso de toma de decisiones en la Asamblea Legislativa.

Palabras Clave

Poder Legislativo, Parlamento, Toma de Decisiones, Transfuguismo parlamentario, Costa Rica.

\section{The Role of "Comisiones Plenas" in the legislative dynamics in Costa Rica (1998-2010)}

ABSTRACT

This text pretends to contribute to the understanding of Legislative dynamics in Costa Rica, by the study of "Comisiones Plenas" role in law approval between 1998 and 2010. By the analysis of power relationships distribution and changes derived of parlamentary faithless, the determination of different scenarios present in "Comisiones Plenas" during the studied period and their impact in the decision making process in the Legislative Assembly is pursued.

KEY WORDS

Legislature, Parliament, Decision Making, Parlamentary Faithless, Costa Rica.

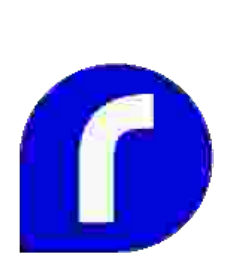

José Andrés Díaz González
Licenciado en Ciencias Políticas. Estudiante de la Maestría Académica en Historia de la Universidad de Costa Rica. Profesor e Investigador de la Escuela de Ciencias Políticas de la Universidad de Costa Rica, e Investigador del Instituto de Estudios Sociales en Población de la Universidad Nacional. Correo electrónico: joseandres.diaz@ucr.ac.cr 


\section{El papel de las Comisiones Plenas en la dinámica legislativa en Costa Rica (1998-2010)*}

Los Estados democráticos modernos han encontrado en el Congreso ${ }^{1}$ el espacio institucional en el cual los diferentes grupos políticos representan y defienden los intereses de la población, a partir de su ideología y visión de mundo. Este es un espacio deliberativo por excelencia, en el cual se pretende realizar un proceso de toma de decisiones que permita consensuar las diferentes posiciones e intereses de los actores políticos.

Por ello es relevante el estudio del Congreso como parte fundamental del sistema político, por ser el lugar donde la voluntad popular converge a partir de la distribución de poder determinada por medio de los procesos electorales. En el caso de Costa Rica, existen múltiples investigaciones centradas en el estudio y análisis del sistema electoral y de partidos políticos, los cuales buscan comprender las causas de sus transformaciones a partir de las preferencias del electorado (Alfaro, 2006; Fernández, 2000; Rojas, 2003), así como por los cambios ocurridos en la gobernanza electoral, entendida esta como las normas y pautas que regulan los procesos electorales (Picado, 2009; Sobrado, 2007), y aún los estudios que buscan analizar integralmente el sistema político costarricense le dan especial relevancia al comportamiento del sistema electoral; no obstante, la mayoría de las investigaciones realizadas sobre el tema no profundizan en cómo han afectado los cambios en el sistema de partidos políticos en la dinámica parlamentaria costarricense $\mathrm{y}$, en muchos casos, se supone la labor de este como una "caja negra" o, por otro lado, se concluye que la alta fragmentación del sistema electoral incide en la ingobernabilidad y parálisis que afectan el proceso de toma de decisiones en el seno del Congreso. Surge así la necesidad de dirigir esfuerzos en la búsqueda de una mayor comprensión acerca de cómo la
* El presente artículo expone algunas de las conclusiones del proyecto de investigación "Dinámica parlamentaria y proceso de toma de decisiones en la Asamblea Legislativa de Costa Rica (1962-2010)" ( $N^{\circ} 213-\mathrm{B} 0-180$ ), realizada en la Escuela de Ciencias Políticas de la Universidad de Costa Rica durante 2010.

El autor desea agradecer a los evaluadores del presente artículo por sus comentarios y observaciones sobre el mismo. No obstante, cualquier error $u$ omisión que el artículo presente es únicamente

responsabilidad del autor.

1. En el presente documento se utilizarán los términos Congreso, Asamblea Legislativa, Parlamento y Poder Legislativo, como sinónimos, sin profundizar en las diferencias teóricoconceptuales que puedan existir entre ellos. 
dinámica legislativa costarricense ha variado a lo largo del tiempo, así como de identificar los principales motivos que han ocasionado dicho cambio, y esclarecer cómo los elementos políticos, estructurales e institucionales han incidido en los procesos de toma de decisiones en la Asamblea Legislativa.

Para conocer mejor el funcionamiento interno de la Asamblea Legislativa se debe estudiar el comportamiento de los partidos políticos al interior del Congreso y los cambios en la dinámica de los procesos de toma de decisiones y su relación con los cambios en la representatividad y el sistema político costarricense. En este caso particular se analiza el desempeño de las Comisiones Legislativas Plenas de la Asamblea Legislativas, las cuales fueron instituidas con el propósito de servir como mecanismos que faciliten y agilicen el proceso de discusión y aprobación de leyes en el parlamento costarricense.

Se analiza los cambios y funcionamientos en la dinámica de las Comisiones Plenas en la primera década del siglo XXI (1998-2010), debido a que se identifica en este periodo la transición de un sistema de partidos políticos bipartidista a uno multipartidista (Alfaro, 2006); por lo cual se espera observar si dicha transición ha afectado o influido en el funcionamiento de estos órganos legislativos, afectando así el desempeño de la Asamblea Legislativa.

Se debe aclarar que si bien este artículo se concentra en analizar los cambios en las cuotas de poder de los partidos políticos representados en la Comisiones Plenas y, de esta manera, su capacidad de influir en los procesos de votación de estos órganos legislativos; en ningún momento se desea obviar la existencia de factores externos (como por ejemplo: grupos de presión, cambios en la coyuntura política nacional o internacional, intervención de otros Poderes del Estado, etc.) que pueden intervenir, modificar o influir en las tendencias de votación de los grupos políticos representados en la Asamblea Legislativa.

De esta manera, dada la existencia de múltiples elementos que pueden intervenir en los procesos de negociación y toma de decisiones en el Poder Legislativo, lo que se pretende es aportar en la consideración de un factor adicional para la compresión de las dinámicas que acontecen en la Asamblea Legislativa, esta es la capacidad de influir en la aprobación o rechazo de un proyecto de ley, que tiene un partido político a partir del número de votos con los que cuenta o controla.

En el ejercicio moderno de la democracia, se necesita tanto de procesos de agregación de intereses y preferencias como procesos integradores para crear cierta unidad, orden y confianza en las instituciones, procesos, organizaciones y demás partes del sistema como tal (Rivas, 1997). De esta manera, el Poder Legislativo, como espacio de representación y 
confrontación política, tiene el deber de realizar dichos procesos como parte fundamental de los sistemas democráticos. No obstante, la labor del Congreso será reflejo de la representatividad, polarización política y volatilidad del sistema de partidos políticos y de la sociedad en general; esto repercutirá directamente en su labor legislativa, y generará escenarios que dificultarán o facilitarán el proceso de toma de decisiones en su seno.

Por lo tanto, es de suma importancia entrar a estudiar las dinámicas y cambios en los procesos de toma de decisiones en el interior de la Asamblea Legislativa, para así identificar cómo las relaciones de poder, la formación de coaliciones, la polarización ideológica y los problemas de representatividad que acontecen en la sociedad costarricense, afectan los procesos parlamentarios.

Lo anterior es importante de tener en cuenta, ya que a pesar de la existencia de intereses, grupos y coyunturas externas e internas que pueden influir en la dinámica legislativa de toma de decisiones, al final las decisiones a lo interno de la Asamblea Legislativa se resuelven mediante procesos de votación, lo cual implica la necesidad de contemplar el peso que tiene cada partido político representado en el congreso para conformar coaliciones ganadoras (grupos con el número de votos necesarios para aprobar o rechazar una decisión) y cómo esto puede aumentar o disminuir su capacidad de negociación.

\section{Las Comisiones Legislativas Plenas entre 1998 y 2010}

Las Comisiones Legislativas Plenas se crean en 1993 mediante la modificación del artículo 124 de la Constitución Política de Costa Rica: "La Asamblea Legislativa puede delegar, en comisiones permanentes, el conocimiento y la aprobación de proyectos de ley. No obstante, la Asamblea podrá avocar, en cualquier momento, el debate o la votación de los proyectos que hubiesen sido objeto de delegación". De esta manera, las Comisiones Legislativas Plenas son entes con la capacidad de aprobar leyes por sí mismas, sin necesidad de llevarlos al Plenario, siempre y cuando estas leyes no sean de materia exclusiva de conocimiento del Plenario Legislativo.

Así, las Comisiones Legislativas Plenas son producto de la evolución del sistema parlamentario, y son creadas como mecanismos para generar una gestión legislativa más eficiente (Muñoz, 1997), lo anterior lleva a formular la siguiente pregunta: ¿Han podido las Comisiones Legislativas Plenas incidir positivamente en la gestión parlamentaria costarricense? 


\section{Gráfico 1}

Comparación del total de leyes aprobadas con las leyes aprobadas en Comisiones Plenas por legislatura (1998-2010)

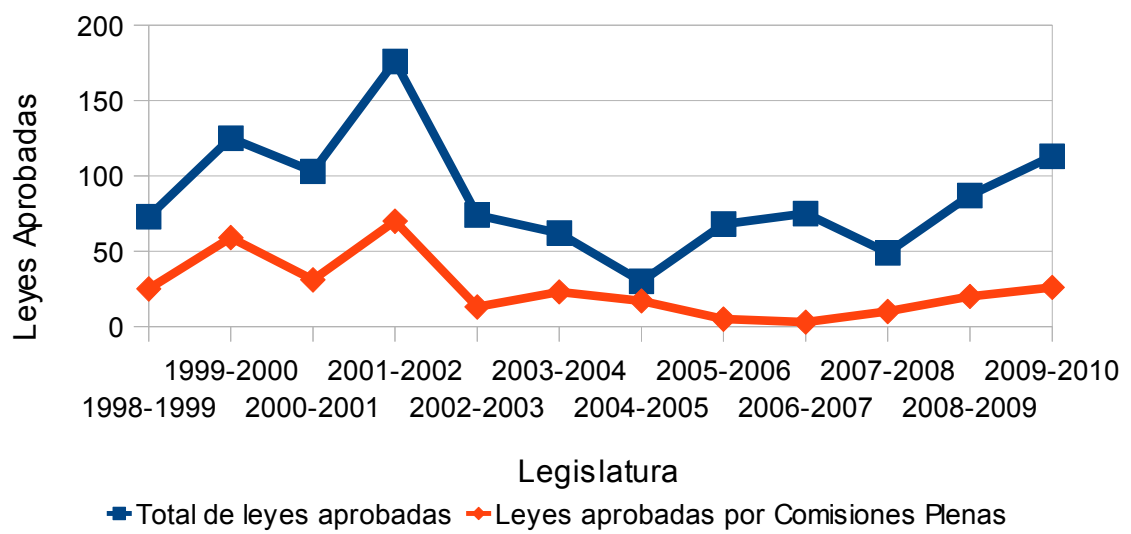

Fuente: Construcción propia, a partir de datos proporcionados por la Unidad de Análisis de la Gestión Parlamentaria del Departamento de Servicios Parlamentarios de la Asamblea Legislativa de Costa Rica. Octubre, 2010.

El gráfico 1 muestra una comparación entre el número de leyes aprobadas por la Asamblea Legislativa, y el número de leyes aprobadas en las Comisiones Legislativas Plenas, entre 1998 y 2010. Como se puede observar, entre la legislatura 1998-1999 y 2002-2003, el Plenario y las Comisiones Plenas mantienen casi el mismo comportamiento. Es decir, el comportamiento de las Comisiones Plenas parece ser un reflejo de lo que ocurre en el Plenario Legislativo.

Pero a partir de la legislatura 2003-2004 esta situación cambia, y las dinámicas de estos órganos legislativos se comportan de forma diferente. Algunos puntos que Ilaman la atención son la legislatura 2004-2005 donde las Comisiones Legislativas Plenas son las que aportan la mayor parte de leyes aprobadas por el Congreso durante dicho año; y las legislaturas 2005-2006 y 2006-2007, donde las Comisiones Plenas solo aportan el 7,35\% y $4 \%$, respectivamente, de las leyes aprobadas (Cuadro 1).

Así, entre la legislatura 1998-1999 y 2009-2010, el papel que parecen jugar las comisiones legislativas plenas es muy cambiante, ya que si bien en promedio aportan cerca del $28 \%$ de las leyes aprobadas en ese periodo, existen grandes fluctuaciones en su actuación, pasando de años donde aportan incluso el $60 \%$ de toda la legislación aprobada, a años donde solo aportan el $4 \%$. 
Cuadro 1. Leyes aprobadas por legislatura en el Plenario Legislativo y en las Comisiones Legislativas Plenas. Asamblea Legislativa, 1998-2010 (absolutos y relativos)

\begin{tabular}{cccccc}
\hline \multirow{2}{*}{ Legislatura } & \multicolumn{2}{c}{ Plenario Legislativo } & \multicolumn{2}{c}{ Comisiones Plenas } & \multirow{2}{*}{ Total } \\
\cline { 2 - 4 } & Absoluto & Relativo & Absoluto & Relativo & \\
\hline $1998-1999$ & 48 & $65.75 \%$ & 25 & $34.25 \%$ & 73 \\
$1999-2000$ & 66 & $52.80 \%$ & 59 & $47.20 \%$ & 125 \\
$2000-2001$ & 72 & $69.90 \%$ & 31 & $30.10 \%$ & 103 \\
$2001-2002$ & 106 & $60.23 \%$ & 70 & $39.77 \%$ & 176 \\
$2002-2003$ & 61 & $82.43 \%$ & 13 & $17.57 \%$ & 74 \\
$2003-2004$ & 39 & $62.90 \%$ & 23 & $37.10 \%$ & 62 \\
$2004-2005$ & 13 & $43.33 \%$ & 17 & $56.67 \%$ & 30 \\
$2005-2006$ & 63 & $92.65 \%$ & 5 & $7.35 \%$ & 68 \\
$2006-2007$ & 72 & $96.00 \%$ & 3 & $4.00 \%$ & 75 \\
$2007-2008$ & 39 & $79.59 \%$ & 10 & $20.41 \%$ & 49 \\
$2008-2009$ & 67 & $77.01 \%$ & 20 & $22.99 \%$ & 87 \\
$2009-2010$ & 87 & $76.99 \%$ & 26 & $23.01 \%$ & 113 \\
\hline
\end{tabular}

Fuente: Construcción propia,a partir de datos proporcionados por la Unidad de Análisis de la Gestión Parlamentaria del Departamento de Servicios Parlamentarios de la Asamblea Legislativa de Costa Rica. Octubre, 2010

El gráfico 2 muestra que el aporte total de las Comisiones Legislativas Plenas al número de leyes aprobadas tiende a disminuir de manera global en este tiempo, pasando de un $28 \%$ en el periodo de $1998-2002$, a un $15 \%$ en el periodo 2006-2010. Entonces ¿Cuál es el impacto real de las Comisiones Legislativas Plenas en la dinámica Parlamentaria costarricense?

\section{Gráfico 2}

Comparación del total de leyes aprobadas con las leyes aprobadas en Comisiones Plenas por periodo de Gobierno (1998-2010)

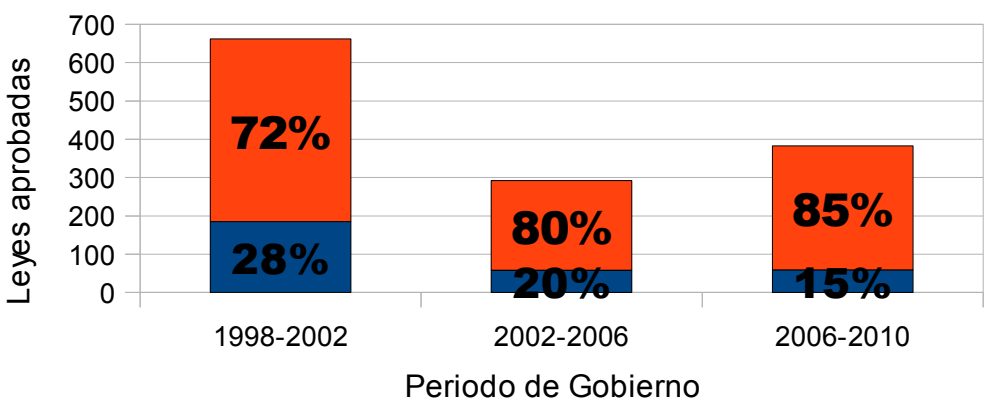

- Leyes aprobadas por Comisiones Plenas

$\square$ Total de leyes aprobadas

Fuente: Construcción propia, a partir de datos proporcionados por la Unidad de Análisis de la Gestión Parlamentaria del Departamento de Servicios Parlamentarios de la Asamblea Legislativa de Costa Rica. Octubre, 2010 


\section{Gráfico 3}

Relación de leyes aprobadas por el Plenario Legislativo y las Comisiones Plenas, por legislatura.

Asamblea Legislativa, 1998-2010

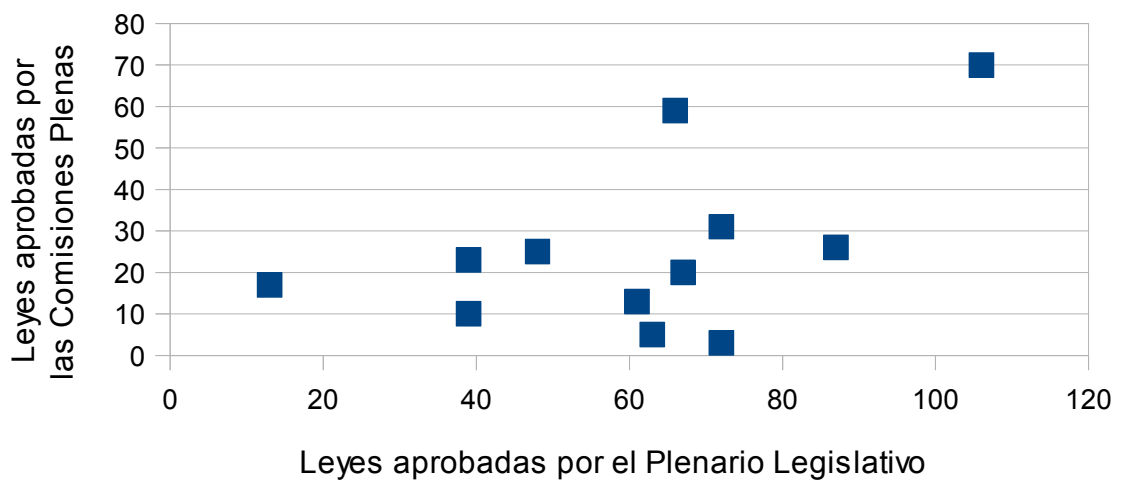

Fuente: Construcción propia, a partir de datos proporcionados por el Departamento de Servicios Parlamentarios de la Asamblea Legislativa de Costa Rica. Octubre, 2010

El gráfico 3 muestra la relación existente entre el número de leyes aprobadas por el Plenario Legislativo y el número de leyes aprobadas por las Comisiones Legislativas Plenas. Se observa que la relación entre ambas variables es algo dispersa. El coeficiente de correlación entre estas variables es de 0,5 lo cual indica que existe una relación medianamente fuerte entre ambas, no obstante, el coeficiente de determinación $\left(\mathrm{R}^{2}\right)$ o poder explicativo de dicha correlación solamente es de 0,25 ; en otras palabras, solo la cuarta parte de las legislaturas pueden explicarse mediante la mediana relación que existe entre las leyes aprobadas por el Plenario Legislativo y las aprobadas por las Comisiones Legislativas Plenas.

Con lo anterior se constata que el impacto de las Comisiones Legislativas Plenas en este período del proceso de aprobación de leyes es baja; con lo que se podría inducir que estos espacios no son aprovechados por la Asamblea Legislativa para la discusión y generación de acuerdos políticos que permita mejorar la gestión y actuación del parlamento costarricense.

Una nueva pregunta surge de los datos observados hasta el momento: ¿Por qué las Comisiones Plenas no han tenido un rol más activo en el desempeño legislativo durante este periodo? A continuación se esbozan algunas respuestas tentativas o hipótesis a dicha pregunta, basadas principalmente en la distribución del poder a lo interno de estos órganos legislativos, las cuales deberán ser confirmadas o refutadas en futuras investigaciones que profundicen en el tema, analizando con más detenimiento las diferentes coyunturas políticas de cada período legislativo estudiado. Como se mencionó al principio de este artículo, no 
se parte de la idea de que solo los factores internos pueden afectar la dinámica de los procesos decisorios en la Asamblea Legislativa, sino que existe una multitud de factores externos que también intervienen en dichos procesos; no obstante, el objetivo del documento es tratar de mostrar cómo puede intervenir la distribución del poder en la labor de las Comisiones Plenas. Lo anterior, en procura de aportar conocimiento sobre uno de los múltiples factores que deben ser tomados en cuenta para una mejor comprensión del funcionamiento del Poder Legislativo en Costa Rica.

El artículo 124 de la Constitución política de Costa Rica establece que:

La Asamblea nombrará las comisiones permanentes con potestad legislativa plena, de manera que su composición refleje, proporcionalmente, el número de diputados de los partidos políticos que la componen. La delegación deberá ser aprobada por mayoría de dos tercios de la totalidad de los miembros de la Asamblea, y la avocación, por mayoría absoluta de los diputados presentes.

Esto es importante ya que la forma en que se encuentran conformadas las comisiones puede incidir en elementos como los proyectos que sean delegados a ellas por el Plenario Legislativo, así como en la facilidad de alcanzar acuerdos y tomar decisiones, o en el control de las Comisiones Legislativas por parte del partido de Gobierno, entre otros.

\begin{tabular}{|c|c|c|c|c|c|c|}
\hline $\begin{array}{l}\text { Partido } \\
\text { Político } \\
\end{array}$ & Plena Primera & $\begin{array}{c}\text { Índice de } \\
\text { Banzhaf }\end{array}$ & Plena Segunda & $\begin{array}{l}\text { Índice de } \\
\text { Banzhaf }\end{array}$ & Plena Tercera & $\begin{array}{c}\text { İndice de } \\
\text { Banzhaf }\end{array}$ \\
\hline$\overline{P L N}$ & 7 & 0.0909 & 8 & 0.1667 & 8 & 0.1667 \\
\hline PUSC & 9 & 0.6364 & 9 & 0.5 & 9 & 0.5 \\
\hline FD & 1 & 0.0909 & 1 & 0.1667 & 1 & 0.1667 \\
\hline PIN & 1 & 0.0909 & - & - & - & - \\
\hline PALA & 1 & 0.0909 & - & - & - & - \\
\hline $\mathrm{ML}$ & - & - & - & - & 1 & 0.1667 \\
\hline $\mathrm{RC}$ & - & - & 1 & 0.1667 & - & - \\
\hline
\end{tabular}

Fuente: Construcción propia, Noviembre, 2010

El cuadro 2 muestra la distribución de escaños, así como el índice de poder de Banzharf, para las Comisiones Legislativas Plenas en el periodo 1998-2002. El índice de Banzhaf es un indicador del poder o capacidad de influir en la adopción de una decisión que tiene un agente o jugador, en los casos en que las decisiones se toman por votación. El valor de Banzhaf asigna a un jugador $i$ la media aritmética de las contribuciones que dicho jugador hace a las coaliciones que se puede unir. En un juego simple, o de votación ponderada, un jugador solo aporta algún beneficio a la coalición ganadora en la que es crítico, es decir, en donde él se convierte en el pivote para lograr que la coalición se convierta en ganadora (Dubey y Shapley, 1979). 
La Comisión Legislativa Plena Segunda y la Plena Tercera presentan la misma distribución de poder, donde el Partido Unidad Social Cristiana (PUSC) -que en dicho periodo fungía como partido de Gobierno- domina las Comisiones, y los restantes partidos comparten la misma cuota de poder. En la Comisión Plena Primera la situación es similar, salvo que hay una mayor cantidad de partidos políticos representados. Lo anterior provoca que la cuota de poder del PUSC sea superior.

Cuadro 3. Leyes aprobadas por legislatura por las Comisiones Legislativas Plenas. Asamblea Legislativa, 1998-2002

\begin{tabular}{ccccc}
\hline Legislatura & Total & $\begin{array}{c}\text { Plena } \\
\text { Primera }\end{array}$ & $\begin{array}{c}\text { Plena } \\
\text { Segunda }\end{array}$ & $\begin{array}{c}\text { Plena } \\
\text { Tercera }\end{array}$ \\
\hline $1998-1999$ & 25 & 8 & 7 & 10 \\
$1999-2000$ & 59 & 18 & 25 & 16 \\
$2000-2001$ & 31 & 10 & 10 & 11 \\
$2001-2002$ & 70 & 29 & 23 & 18 \\
\hline Total & $\mathbf{1 8 5}$ & $\mathbf{6 5}$ & $\mathbf{6 5}$ & $\mathbf{5 5}$ \\
\hline
\end{tabular}

Fuente: Construcción propia, a partir de datos proporcionados por la Unidad de Análisis de la Gestión Parlamentaria del Departamento de Servicios Parlamentarios de la Asamblea Legislativa de Costa Rica. Octubre, 2010

No obstante esta situación, durante el periodo 1998-2002, se aprobaron la misma cantidad de leyes en la Plena Primera y Segunda, lo cual parece indicar que el número de partidos políticos representados en estas, así como la distribución del poder en las mismas, no fue un elemento de peso que afectara de manera directa el número de leyes que se aprobó en cada comisión. Como contraste, la Plena Tercera, cuya distribución de poder era idéntica a la Plena Segunda, aprobó diez leyes menos en dicho periodo (Cuadro 3).

Cuadro 4. Distribución de escaños en las Comisiones Legislativas Plenas e índice de Banzhaf. Asamblea Legislativa, 2002-2006

\begin{tabular}{lcccccc}
\hline $\begin{array}{l}\text { Partido } \\
\text { Político }\end{array}$ & Plena Primera & $\begin{array}{c}\text { Índice de } \\
\text { Banzhaf }\end{array}$ & Plena Segunda & $\begin{array}{c}\text { Índice de } \\
\text { Banzhaf }\end{array}$ & Plena Tercera & $\begin{array}{c}\text { Índice de } \\
\text { Banzhaf }\end{array}$ \\
\hline PLN & 6 & 0.33 & 7 & 0.33 & 5 & 0.2308 \\
PUSC & 6 & 0.33 & 6 & 0.33 & 7 & 0.3846 \\
ML & 2 & 0 & 2 & 0 & 2 & 0.0769 \\
PAC & 5 & 0.33 & 4 & 0.33 & 4 & 0.2308 \\
RC & - & - & - & - & 1 & 0.0769 \\
\hline
\end{tabular}

Fuente: Construcción propia. Noviembre, 2010

Para el periodo 2002-2006 se encuentra que las Comisiones Legislativas Plena Primera y Segunda tienen la misma distribución de poder, donde se pueden observar dos hechos llamativos: el primero, que no hay un partido político dominante, ya que tres partidos políticos se reparten el poder por igual; segundo, que a pesar de contar con representantes en dichas 
comisiones, el Partido Movimiento Libertario (ML) no tenía una cuota de poder en estas, lo cual se debe a que la cantidad de votos que controla (dos en cada caso) son insuficientes para aportar en la aprobación de un proyecto, en otras palabras, no era necesario para conformar coaliciones ganadoras (Cuadro 4).

En el caso de la Comisión Legislativa Plena Tercera (Cuadro 4), el PUSC se destaca como el partido dominante o con la mayor cuota de poder, seguido por el Partido Liberación Nacional (PLN) y el Partido Acción Ciudadana (PAC), y luego por el ML y Renovación Costarricense (RC).

\begin{tabular}{lcccc}
\hline \multicolumn{2}{l}{$\begin{array}{l}\text { Cuadro 5. Leyes aprobadas por legislatura } \\
\text { Plenas. Asamblea Legislativa, }\end{array}$} & por las Comisiones & Legislativas \\
\hline Legislatura & Total & $\begin{array}{c}\text { Plena } \\
\text { Primera }\end{array}$ & $\begin{array}{c}\text { Plena } \\
\text { Segunda }\end{array}$ & $\begin{array}{c}\text { Plena } \\
\text { Tercera }\end{array}$ \\
\hline $2002-2003$ & 13 & 6 & 5 & 2 \\
$2003-2004$ & 23 & 9 & 6 & 8 \\
$2004-2005$ & 17 & 3 & 9 & 5 \\
$2005-2006$ & 5 & 3 & 1 & 1 \\
\hline Total & $\mathbf{5 8}$ & $\mathbf{2 1}$ & $\mathbf{2 1}$ & $\mathbf{1 6}$ \\
\hline
\end{tabular}

Fuente: Construcción propia, a partir de datos proporcionados por la Unidad de Análisis de la Gestión Parlamentaria del Departamento de Servicios Parlamentarios de la Asamblea Legislativa de Costa Rica. Octubre, 2010

Como puede observarse en el cuadro 5, la Comisión Plena Tercera aprobó una menor cantidad de leyes que la Plena Primera y Plena Segunda, durante este periodo. Asimismo, en la Comisión Plena Tercera el PUSC era el partido dominante, y no compartía el poder en cuotas iguales con otros partidos presentes, como ocurrió en las otras comisiones (Cuadro 4).

Lo anterior podría hacer pensar que al tener el PUSC una mayor cuota de poder en esta Comisión, se facilitaría el proceso de toma de decisiones; no obstante los datos revelan que todos los partidos políticos representados en la Comisión Plena Tercera tenían una cuota de poder, es decir, tenían la capacidad de formar coaliciones ganadoras; lo que provocaba que, a diferencia de lo que ocurría en la Plena Primera y Segunda donde solo tres partidos políticos tenían capacidad de decisión, en la Plena Tercera eran cinco los partidos políticos que podían intervenir en la toma de decisiones; esto posiblemente podría provocar que los procesos de negociación en esta Comisión fueran más complejos.

Para el periodo de Gobierno 2006-2010 se encuentra una variación muy importante respecto a la distribución del poder en la Comisiones Plenas. Como se observa en el cuadro 6, en las Comisiones Plenas Primera y Tercera, si bien el PLN es el partido con una cuota de poder mayor, cada agrupación política presente en dichas comisiones mantiene una cuota de poder, es decir, tienen capacidad de intervenir en el proceso de toma de decisiones para aprobar o rechazar los proyectos de ley en ellas 
presentados. No obstante, lo que diferencia a este periodo de Gobierno, es que la Comisión Plena Segunda se encontraba en completo control por parte del PLN; en otras palabras, los restantes partidos políticos representados en dicha comisión no reunían los suficientes votos para intervenir en el proceso de tomas de decisiones.

Cuadro 6. Distribución de escaños en las Comisiones Legislativas Plenas e índice de Banzhaf. Asamblea Legislativa, 2006-2010

\begin{tabular}{lcccccc}
\hline $\begin{array}{c}\text { Partido } \\
\text { Político }\end{array}$ & Plena Primera & $\begin{array}{r}\text { Índice de } \\
\text { Banzhaf }\end{array}$ & Plena Segunda & $\begin{array}{c}\text { Índice de } \\
\text { Banzhaf }\end{array}$ & Plena Tercera & $\begin{array}{c}\text { Índice de } \\
\text { Banzhaf }\end{array}$ \\
\hline PLN & 8 & 0.4615 & 10 & 1 & 9 & 0.6364 \\
PUSC & 1 & 0.0769 & 2 & 0 & 2 & 0.0909 \\
FA & 1 & 0.0769 & 4 & 0 & - & - \\
PAC & 6 & 0.1538 & - & - & 5 & 0.0909 \\
PASE & 1 & 0.0769 & - & - & - & - \\
ML & 2 & 0.1538 & 2 & 0 & 2 & 0.0909 \\
RC & - & - & 1 & 0 & 1 & 0.0909 \\
\hline
\end{tabular}

Fuente: Construcción propia. Noviembre, 2010

Podría pensarse que el control absoluto que tenía el PLN en la Comisión Plena Segunda durante dicha administración fuera aprovechado por esta agrupación política, ya que la Plena Segunda fue la comisión más productiva durante esos cuatros años (Cuadro 7). Sin embargo, la diferencia con las otras dos comisiones no es muy significativa; asimismo, llama la atención que en los dos primeros años de dicho gobierno solo se aprobaron cuatro leyes en la Comisión Plena Segunda, a pesar de estar completamente controlada por el partido de gobierno, misma cantidad de leyes aprobadas por la Comisión Plena Tercera -a pesar de la fragmentación de poder a lo interno de esta y que en la primera legislatura no se aprobara ninguna ley en dicha comisión- y una menos que en la Comisión Plena Primera, que logró aprobar cinco leyes en los primeros dos años de Gobierno.

Cuadro 7. Leyes aprobadas por legislatura por las Comisiones Legislativas Plenas. Asamblea Legislativa, 2006-2010

\begin{tabular}{ccccc}
\hline Legislatura & Total & $\begin{array}{c}\text { Plena } \\
\text { Primera }\end{array}$ & $\begin{array}{c}\text { Plena } \\
\text { Segunda }\end{array}$ & $\begin{array}{c}\text { Plena } \\
\text { Tercera }\end{array}$ \\
\hline $2006-2007$ & 3 & 1 & 2 & 0 \\
$2007-2008$ & 10 & 4 & 2 & 4 \\
$2008-2009$ & 20 & 6 & 10 & 4 \\
$2009-2010$ & 26 & 7 & 10 & 9 \\
\hline Total & $\mathbf{5 9}$ & $\mathbf{1 8}$ & $\mathbf{2 4}$ & $\mathbf{1 7}$
\end{tabular}

Fuente: Construcción propia, a partir de datos proporcionados por la Unidad de Análisis de la Gestión Parlamentaria del Departamento de Servicios

Parlamentarios de la Asamblea Legislativa de Costa Rica. Octubre, 2010 
Los datos anteriores parecen indicar una falta de interés de los legisladores y las legisladoras por utilizar las Comisiones Plenas como espacios que permitan agilizar la discusión parlamentaria y el proceso de aprobación de leyes. Parece, por lo tanto, que las Comisiones Plenas se presentan como espacios estratégicos donde son enviados proyectos puntuales que a la mayoría parlamentaria les interesa aprobar con cierta celeridad. Además, parece que existe una tendencia por utilizar de manera más selectiva este instrumento parlamentario ya que, como se aprecia en el gráfico 2, el porcentaje total de leyes aprobadas por la Asamblea Legislativa que se realiza en las Comisiones Plenas tiende a disminuir desde el periodo 1998-2002.

No se puede obviar que uno de los motivos que puede dificultar la toma de decisiones de las Comisiones Plenas es que estas solo se reúnen obligatoriamente un día a la semana y por un espacio generalmente no mayor a dos horas; lo cual podría considerarse como un obstáculo en el trabajo de los legisladores en dichos espacios parlamentarios. No obstante, los proyectos de ley que son analizados en dichas comisiones son delegados por el Plenario Legislativo, por tanto, se podría esperar que estos hayan sido discutidos y consensuados por un grupo importante de legisladores, lo que debería facilitar el trabajo en dichas comisiones, así como el proceso de toma de decisiones en estas.

\section{Efectos del transfuguismo en las Comisiones Legislativas Plenas: 1998-2010}

La legislación costarricense permite a un diputado separarse del partido político por el cual fue electo, sin que esto implique que pierda su escaño. Este transfuguismo parlamentario afecta la dinámica de la Asamblea Legislativa y la relación de poder entre los diferentes grupos políticos. Anteriormente se analizaron los datos con la conformación establecida en ellas a partir de los partidos políticos que participaron en el proceso electoral, ya que dichas conformaciones son las consideradas en primera instancia por el Presidente de la Asamblea Legislativa para conformar las Comisiones el $1^{\circ}$ de mayo de la primera legislatura, y tradicionalmente no varía a pesar de las posibles separaciones de diputados. Así, en este apartado se busca observar si el transfuguismo ha impactado de manera significativa el trabajo de las Comisiones Legislativas Plenas durante la primera década del siglo XXI.

El cuadro 8 muestra cómo varía el número de agrupaciones políticas ${ }^{2}$ presentes en las Comisiones Legislativas Plenas y su comparación con el número de leyes aprobadas por estas cada legislatura. La correlación entre ambas variables es de $-0,48$, esto indica que existe una correlación inversa moderadamente fuerte entre el número de agrupaciones políticas y la cantidad de leyes aprobadas en las Comisiones Plenas, en otras palabras, a más grupos políticos conforman las Comisiones Plenas, menos leyes logran ser aprobadas (Gráfico 4). No obstante, el coeficiente
2. Por agrupación política se entiende los diputados independientes o los bloques de diputados que se conforman a partir de los legisladores que dejan los partidos políticos por los cuales fueron electos. 
de determinación de dicha correlación es apenas de 0,23 , lo cual indica que su poder explicativo es bajo, ya que solo aproximadamente una cuarta parte de los casos pueden explicarse a partir de la relación de dichas variables.

Cuadro 8. Cambio en el número de agrupaciones políticas presentes en las Comisiones Legislativas Plenas y cantidad de leyes aprobadas. Asamblea Legislativa, 1998-2010

\begin{tabular}{lcccccc}
\hline \multirow{2}{*}{ Legislatura } & \multicolumn{2}{c}{ Plena Primera } & \multicolumn{2}{c}{ Plena Segunda } & \multicolumn{2}{c}{ Plena Tercera } \\
\cline { 2 - 7 } & $\begin{array}{c}\text { Agrupaciones } \\
\text { Políticas }\end{array}$ & $\begin{array}{c}\text { Leyes } \\
\text { Aprobadas }\end{array}$ & $\begin{array}{c}\text { Agrupaciones } \\
\text { Políticas }\end{array}$ & $\begin{array}{c}\text { Leyes } \\
\text { Aprobadas }\end{array}$ & $\begin{array}{c}\text { Agrupaciones } \\
\text { Políticas }\end{array}$ & $\begin{array}{c}\text { Leyes } \\
\text { Aprobadas }\end{array}$ \\
\hline $1998-1999$ & 5 & 8 & 4 & 7 & 4 & 10 \\
$1999-2000$ & 5 & 18 & 4 & 25 & 4 & 16 \\
$2000-2001$ & 5 & 10 & 4 & 10 & 4 & 11 \\
$2001-2002$ & 5 & 29 & 4 & 23 & 4 & 18 \\
$2002-2003$ & 7 & 6 & 5 & 5 & 6 & 2 \\
$2003-2004$ & 8 & 9 & 5 & 6 & 6 & 8 \\
$2004-2005$ & 8 & 3 & 5 & 9 & 8 & 5 \\
$2005-2006$ & 8 & 3 & 5 & 1 & 8 & 1 \\
$2006-2007$ & 6 & 1 & 5 & 2 & 5 & 0 \\
$2007-2008$ & 6 & 4 & 5 & 2 & 6 & 4 \\
$2008-2009$ & 7 & 6 & 5 & 10 & 6 & 4 \\
$2009-2010$ & 7 & 7 & 5 & 10 & 6 & 9 \\
\hline
\end{tabular}

*Por agrupación política se entiende los diputados independientes o los bloques de diputados que se conforman apartir de los legisladores que dejan los partidos políticos por los cuales fueron electos.

Fuente: Construcción propia, a partir de datos proporcionados por la Unidad de Análisis de la Gestión Parlamentaria del Departamento de Senvicios Parlamentarios de la Asamblea Legislativa de Costa Rica. Noviembre, 2010.

Sin embargo, otra forma de tratar de determinar el impacto del transfuguismo en las Comisiones Plenas es observar cómo este varía la distribución de las cuotas de poder a lo interno de dichas Comisiones. Así, por ejemplo, en el cuadro 4 se mostraba que el ML no tenía ninguna cuota de poder en las Comisiones Plenas Primera y Segunda tal y como habían sido conformadas originalmente; no obstante, el transfuguismo cambia la relación de poder a lo interno de dichas comisiones permitiendo al ML captar una cuota de poder que le permite intervenir de manera más efectiva en el proceso de toma de decisiones de dichas comisiones.

El gráfico 5 muestra cómo varía la relación entre el número de leyes aprobadas y la cantidad de agrupaciones políticas con una cuota de poder efectiva para intervenir en el proceso de toma de decisiones. La correlación entre ambas variables es de $-0,17$; si bien continúa siendo negativa la relación, esta es muy cercana a 0 , lo cual es un indicio de una débil relación entre ambas. Esto se confirma con el coeficiente de determinación de dicha correlación el cual es 0,03. 


\section{Gráfico 4}

Relación entre número de agrupaciones políticas y leyes aprobadas en las Comisiones Plenas por legislatura.

Asamblea Legislativa, 1998-2010

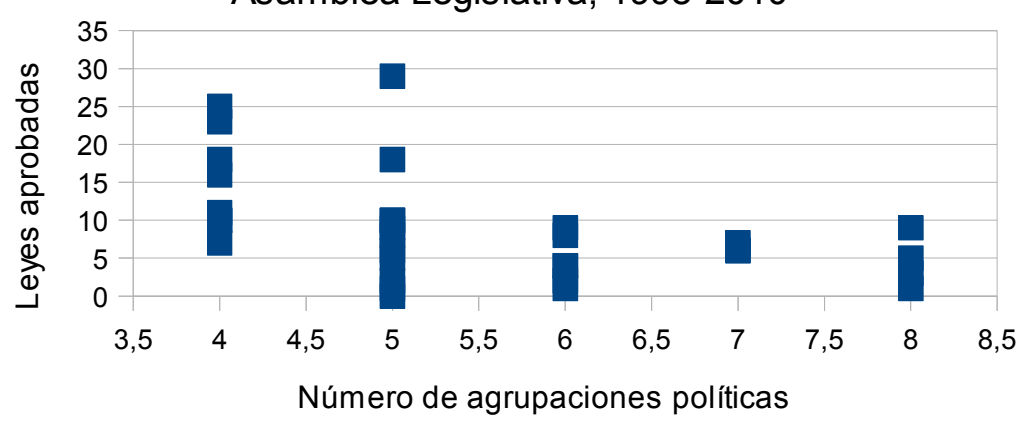

Fuente: Construcción propia, a partir de datos proporcionados por la Unidad de Análisis de la Gestión Parlamentaria del Departamento de Servicios Parlamentarios de la Asamblea Legislativa de Costa Rica.

\section{Gráfico 5}

Correlación entre número de grupos políticos con poder y leyes aprobadas en las Comisiones Plenas por legislatura. Asamblea Legislativa, 1998-2010

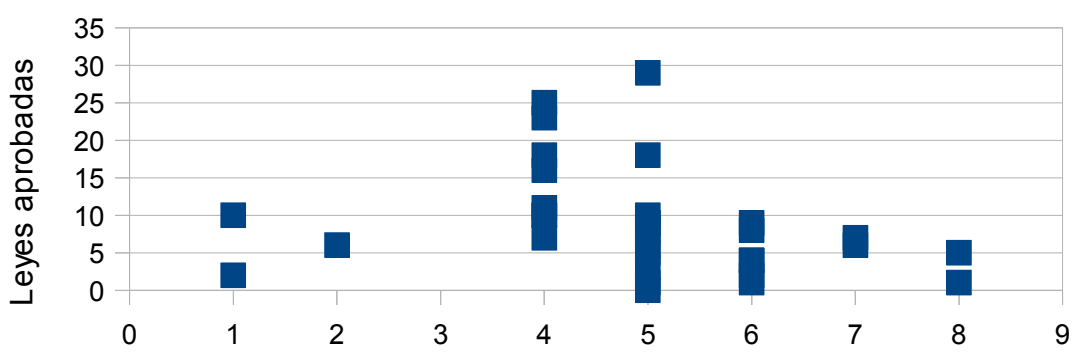

Número de grupos políticos con poder

Fuente: Construcción propia, a partir de datos proporcionados por la Unidad de Análisis de la Gestión Parlamentaria del Departamento de Servicios Parlamentarios de la Asamblea Legislativa de Costa Rica. Noviembre, 2010

Estos datos parecen confirmar la hipótesis de que la crisis de gobernabilidad que algunos analistas sostienen que atraviesa el sistema político costarricense y, en especial, la Asamblea Legislativa, no se debe a la "excesiva" fragmentación del parlamento, sino que parece responder más a variables relacionadas con la gestión política y la capacidad de diálogo de los grupos políticos para alcanzar puntos de acuerdo. 


\section{Conclusión}

Las Comisiones Legislativas Plenas durante la primera década del siglo XXI no han tenido un fuerte impacto en la dinámica parlamentaria, y su contribución al proceso de aprobación de leyes durante este periodo resulta ser bastante puntual. Los datos expuestos permiten observar que no es la distribución del poder, ni el aumento del número de agrupaciones políticas en la Asamblea Legislativa durante este periodo lo que parece incidir de manera directa en el desempeño de estos órganos legislativos; esto lleva a pensar que las explicaciones relacionadas con la existencia de un mal desempeño o "parálisis parlamentaria" debidas a la presencia de un escenario multipartidista no parecen ser acertadas para este caso.

Muchos actores internos y externos a la Asamblea Legislativa claman por la necesidad de reformar el reglamento del Primer Poder de la República, como el medio para enfrentar los cambios en el escenario político, en procura de desempeño legislativo más eficiente (Matamoros, 2011, 30 de agosto), por lo cual incluso diputados y diputadas han tratado de promover reformas al Reglamento Legislativo para evitar acciones que ellos consideran como "filibusterismo":

Entre los principales males que le aquejan a nuestro anticuado reglamento se encuentra su permisividad al "filibusterismo", práctica en la cual un diputado o un grupo de ellos pueden paralizar la tramitación de un tema o proyecto, apoyados en la interminable discusión de los asuntos producto del uso irrefrenado de la palabra, de carretillos de mociones de reiteración y de la inexistencia de plazos de votación y caducidad de los proyectos, así como su excesivo formalismo y rigidez que atentan contra el derecho parlamentario el cual se caracteriza por ser espontáneo, dinámico y flexible (Asamblea Legislativa, Proyecto $\mathrm{N}^{\circ}$ 18.141).

No obstante, los datos analizados parecen mostrar que el proceso de toma de decisiones tanto en las Comisiones Plenas, como en general en la Asamblea Legislativa está más influenciado por la capacidad de diálogo, negociación y formación de consenso que tienen los partidos políticos representados en el congreso costarricense, que por las reglas e instancias formales que lo regulan.

Por lo tanto, parece ser que lo dispuesto hace ya diez años por Fernández (2001) sobre el origen del problema de gobernabilidad que afecta a Costa Rica según algunos grupos políticos, aún tiene validez para evaluar la dinámica legislativa costarricense en la primera década del siglo XXI: 
Los lamentos más recientes, emanados del poder y que asumen con ligereza el diagnóstico neoconservador de una ingobernabilidad en ciernes o en pleno curso, no hacen más que esconder o disfrazar la frecuente impericia o relativa incapacidad de la que parecen haber hecho gala algunos de nuestros más recientes gobernantes (Fernández. 2001, p. 570).

Por lo tanto, este autor considera que no es la fragmentación del sistema político lo que ha provocado los problemas de gobernabilidad en Costa Rica, sino la falta de capacidad o gestión política de los gobernantes para alcanzar acuerdos y llevar a buen término los procesos de negociación básicos en una democracia.

Incluso, escenarios legislativos caracterizados por una alta fragmentación y una multiplicidad de actores con poder para intervenir en la toma de decisiones parlamentarias, pueden presentar características que permitan al partido oficialista y al Poder Ejecutivo impulsar su propia agenda:

...si la fragmentación parlamentaria y la polarización sobre la agenda legislativa genera un problema en la capacidad de toma de decisiones del Ejecutivo, podría ser que, dependiendo de la multiplicidad de actores de oposición y su dispersión, del tamaño del contingente legislativo oficialista, y de los niveles de disciplina y cohesión, el presidente y su gabinete cuenten con un mayor margen de opciones para articular coaliciones parlamentarias (Vargas y Petri, 2008, p. 191).

Esto lleva a la necesidad de profundizar en los estudios sobre las capacidades de negociación y formación de consenso de las personas que ocupan una curul legislativa en los distintos periodos de gobierno, así como las estrategias y capacidades que tienen los diferentes grupos políticos de encontrar puntos de convergencia en sus propuestas políticas para el desarrollo de leyes que traten de integrar las diferentes visiones e intereses representados en la Asamblea Legislativa.

\section{Bibliografía}

Alfaro, R. (2006). Elecciones nacionales 2006 en Costa Rica y la recomposición del sistema de partidos políticos. Revista de Ciencia Políticas, 26, 125-137.

Asamblea Legislativa de Costa Rica. (2011). Proyecto № 18.141: Reforma parcial del Reglamento de la Asamblea Legislativa. 
Dubey, P. y Shapley, L. S. (1979). Mathemathical properties of the Banzhaf Power Index Mathematics of Operations Research, 4, 99131.

Fernández, O. (2000). Las reglas de representación parlamentaria: El reinicio de un debate en la Costa Rica de los años noventa. Anuario de Estudios Centroamericanos, 26, 133-145.

Fernández, O. (2001). Representación parlamentaria en la Costa Rica de hoy. En: Rovira Mas, J. (Edit.), La democracia de Costa Rica ante el siglo XXI (559-574). San José: Editorial Universidad de Costa Rica.

Matamoros, J. (2011, 30 de agosto). La necesaria reforma al reglamento legislativo. La Nación. Recuperado de http://www.nacion.com/201108-30/Opinion/la-necesaria-reforma-al-reglamento-legislativo.aspx

Muñoz, H. A. (1997). La Asamblea Legislativa en el sistema constitucional costarricense. San José: IIDH-CAPEL.

Picado, H. (2009). Diseño y transformaciones de la gobernanza electoral en Costa Rica. América Latina Hoy, 51, 95-116.

Rivas, J.A (1997). El neoinstitucionalismo y la revalorización de las instituciones. Reflexión Política, 9, 36-46.

Rojas, M. (2003). Costa Rica: Un sistema de partidos en recomposición. Recuperado en: http://www.flacso.or.cr/fileadmin/documentos/FLACSO/Manuel1.pdf

Sobrado, L. A. (2007). Democratización interna de los partidos políticos en Costa Rica. San José: FLACSO.

Vargas, J. P. y Petri, D. P. (2008). Efectividad Parlamentaria. Incentivos y restricciones coalicionales en Costa Rica y Nicaragua. San José: DEMUCA. 